\title{
AN APPLIED STUDY FOR THE RESTORATION OF A GLASS LANTERN DAMAGED BY THE EXPLOSION AT THE MUSEUM OF ISLAMIC ART IN CAIRO
}

\author{
Mohammed Hefny MOGHAZY ${ }^{1}$, Nagwa Sayed ABDEL RAHIM ${ }^{2}$, Hamdy Abdel Moniem \\ MOHAMMED ${ }^{1}$, Rasha Taha ABBAS ${ }^{2, *}$ \\ ${ }^{1}$ Conservation Lab., Islamic Art Museum, Ministry of Antiquities, Egypt \\ ${ }^{2}$ Conservation Department, Faculty of Archaeology, Fayoum University, Egypt
}

\begin{abstract}
The Museum of Islamic Art in Cairo includes a large and rare collection of glassware, on January 24, 2014 An explosion occurred in the Cairo Security Directorate building, which is opposite the building of the Museum of Islamic Art, which damaged many of these The complaints displayed in the museum, some of them were completely destroyed, some were broken, while some survived The accident is intact. The different damage status of the presented glass complaints is due to the participation of another human damage factor being a disadvantage The museum display, as the glass niches that were most affected by the accident are displayed with a cupboard above it A large metal oven fell due to the explosion above the complaints. The intact glass complaints that survived the explosion as well as the partially damaged complaints were not In a safe position after the explosion, it had to be transported to a safe place, packed, and then transported to a safe place The museum storehouse and the affected person was transferred to the restoration laboratory, and the explosion also resulted in mixing the ancient glass fragments with others From the non-antique glass fragments due to the glass of the Fattarin, as well as the glass windows of the museum. Due to the importance and rarity of the damaged glass complaints, many of these complaints deserve study, as they aim The research is to study the rescue and restoration of one of the glass complaints damaged by the explosion by a stage Sorting and classification, the research also deals with studying the composition of the material effect, the method of manufacture and decoration. The work stages are represented in the stage of salvaging the glass niche partially damaged by the accident by transferring it to A safe place, as well as the stage of recovering the ancient glass fragments, separating them from other non-antique fragments, and then classifying them, And after that, the restoration stages [recording and documentation, examinations and analyses], the digital microscope USB Digital Microscope, the scanning electron microscope equipped with the X-ray scattering unit - SEM, EDX Fluorescence X-ray XRF (cleaning phase Collecting phase Completion phase) The study results in identifying the stages of salvation and restoration of the glass niche in question, as well as the identification of Impact case.
\end{abstract}

Keywords

Blast Accidents, Glass Complaints, Screening Process, Classification Process, Collection, Completion.

\section{Introduction}

On January 24, 2014, an explosion occurred in the Cairo Security Directorate building, which corresponds to the Museum of Islamic Art, which caused damage to many of the antiquities displayed in the museum (Ministry of Antiquities, 2014), and also led to the shattering of many of the archaeological collections on display, and the most affected of these effects were the ceramic antiquities And the glass artifacts, as the number of glass traces affected by the explosion is (52) (Hamdy Abdel Moneim, 2017. )

The glass-magical complaints from the explosion accident were not in a safe position after the accident, so the priority was to save these complaints by transporting them to a safe place and

\footnotetext{
* Corresponding author: rta00@fayoum.edu.eg
} 
wrapping them using the available materials so that the glass niche is coated on all sides so that when a collision occurs to one of the parts of the lantern, the force of the collision is distributed over the bulk of the niche. It is not concentrated on a single part and breaks down (JICA, 2013), and the healthy ones are transferred to the warehouse and the damaged ones to the restoration plant.

While the archaeological glass fragments due to the glass effects affected by the accident mixed with the non-antique fragments due to the glass of the fattarin and the glass windows, so the first step in the restoration of the glass complaints affected by the explosion was to pick up the glass fragments from the middle of the explosion debris and sort them so that they are done Sorting the antique vitreous fractures from the non-archaeological glass fractures, and during the sorting process, the fractures related to the complaints nozzles were placed in separate boxes and the fractures due to the complaints body were placed in separate boxes, as well as the complaints rules were placed in separate boxes in preparation for the classification process intended to separate the fracture Each niche separately.

Where the stages of studying and restoring the glass niche in question are as follows:

- Registration and documentation.

- Examination and analysis.

- Cleaning stage.

- The assembly stage.

- Completion stage.

\section{Conclusion}

1 When such an accident occurs, care must be taken that the antiquities are not dealt with while salvaging them by non-specialists, in order to avoid errors during the salvage process that negatively affect the antiquities.

2 In the event of such a disaster, the correct glass complaints must first be expedited.

And the slightly damaged ones, by packing them and transporting the healthy ones to the warehouse and the damaged ones to the restoration laboratory, then start collecting the broken glass monuments.

3 The collection of any antique fragment, regardless of its small size, should not be overlooked, since this fragment represents the glass niche that will be restored.

4 Care must be taken not to start the restoration of a glass niche damaged by such an accident before making sure that all of its glass fragments are present.

5 It must be taken into account not to rush into the use of insulation or reinforcement material unless the necessity so requires - 
AN APPLIED STUDY FOR THE RESTORATION OF A GLASS LANTERN DAMAGED BY THE EXPLOSION AT THE MUSEUM OF ISLAMIC ART IN CAIRO

6 With the aim of preserving the antiquity, so that the interference with the antiquity is necessary in just preserving it.

Received: February 18, 2018

Accepted: April 23, 2018 